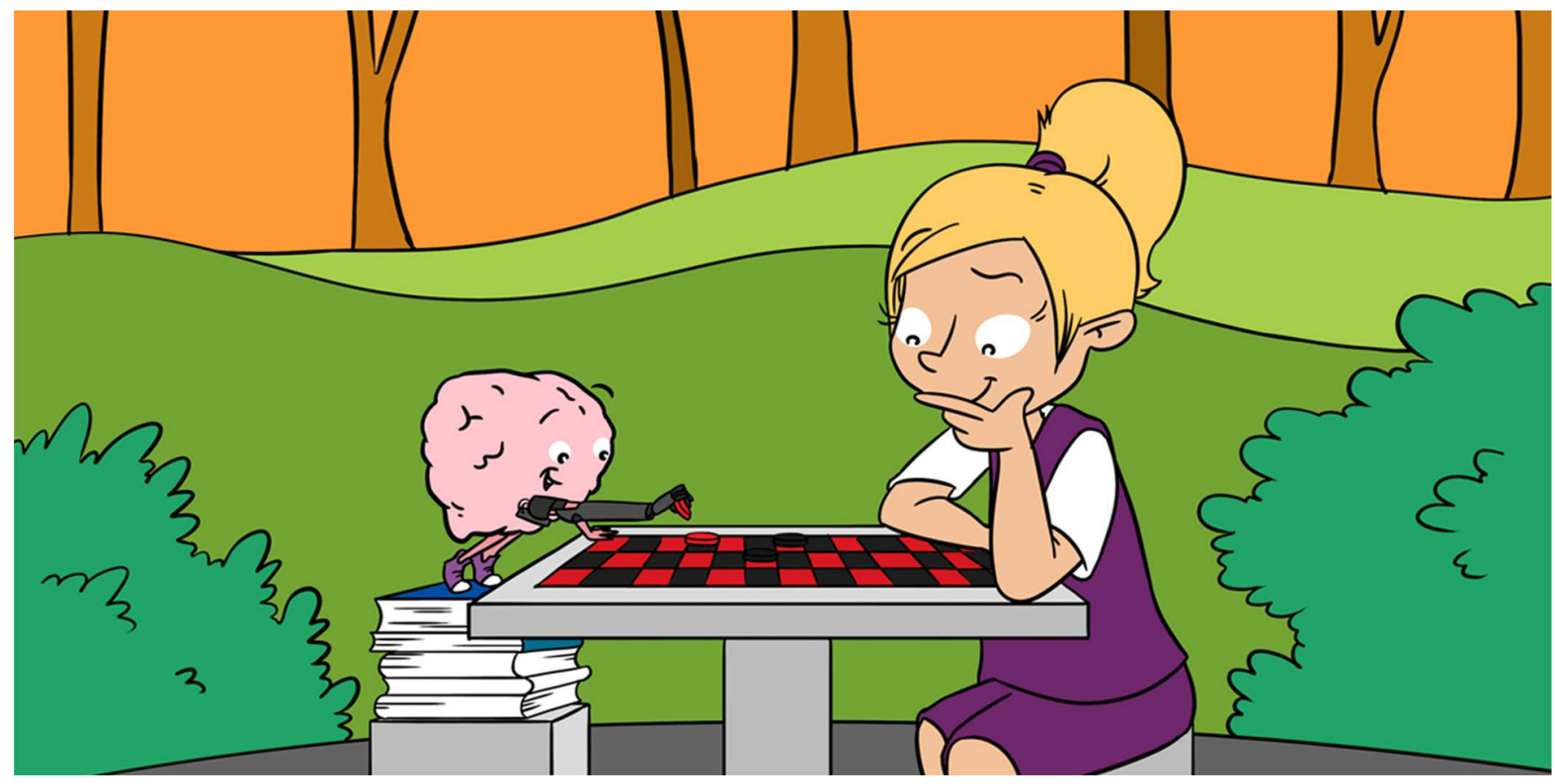

\title{
NATURE'S MASTERPIECE: HOW SCIENTISTS STRUGGLE TO REPLACE THE HUMAN HAND
}

\section{Leonard F. Engels * and Christian Cipriani}

Artificial Hands Area, The BioRobotics Institute, Scuola Superiore Sant'Anna, Pisa, Italy

YOUNG REVIEWERS:

IIS G.

PEANO

AGE: 15

LICEO

VENDRAMINI

AGE: 15
Some people have only one hand or no hands at all. They are missing hands either from birth or because of accidents or illnesses. Hand prostheses are artificial devices used to replace missing hands. "Passive" hands, meaning prosthetic hands that do not actually move, look realistic, are light, robust, and not too expensive. But, to actively grasp things, one needs an "active" prosthesis. These can be simple mechanical hands or complex, expensive robotic hands. All kinds of prostheses have upsides and downsides, but current research focuses mostly on active electrical robotic hands. One big, unsolved challenge is how to enable prosthesis users to feel with their robotic hands. Many different methods have been tried, some requiring surgery, but scientists still cannot fully restore natural sensation.

\section{INTRODUCTION}

It is no coincidence that we ask people to "give us a hand" when we need help. Our hands are crucial for everything from getting out of bed to playing the piano. But there are people who have only one 


\section{PROSTHESIS}

A replacement of a missing body part.

\section{ARTIFICIAL}

Something made by humans; not natural.

BODY-POWERED

Something that is moved by the human body.

\section{EXTERNALLY- POWERED}

Something that is moved with an external energy source, like a battery. hand or no hands at all. Some people are born without one or both hands. Others lose hands through accidents, like car crashes, through illnesses, like blood infections, or in war. Often, things can easily be done with one hand [1]. People can use their teeth, chin, or legs and feet to hold and move things. For example, to try to pull down the zipper of a jacket with one hand, a person may use their teeth to hold the collar. And for tasks that cannot easily be done one-handed, helpful tools exist. However, having two hands makes many tasks easier, like opening a door while carrying something. Besides, we also use our hands to communicate with others, by gesturing and pointing [2].

\section{WHAT IS A HAND PROSTHESIS?}

A prosthesis is an artificial device that imitates the function of a body part. More than half of all people who are missing one or both hands choose to wear a prosthesis at least some of the time [1]. There are two broadly different types: passive prostheses, like cosmetic and passive mechanical hands, and active prostheses, like body-powered and externally-powered hands [1,3].

\section{WHAT ARE "PASSIVE" PROSTHESES?}

The simplest forms of hand prostheses, passive cosmetic prostheses, were already in use more than 2,000 years ago in ancient Egypt (Figure 1A). They serve an aesthetic purpose, meaning they are mainly "for looks," rather than a functional purpose and they are called "passive" prostheses, because they cannot move to actively grasp something. Passive cosmetic hands are still used today, because they can look very life-like, which is important for many wearers. If our society were more accepting of different-looking bodies, people might feel more comfortable in public without a cosmetic prosthesis.

A passive mechanical hand has fingers that are moveable with the help of the other hand or the environment. This means that a mechanical hand can be used to hold something. The first passive mechanical hand was developed and used by the German knight Gottfried "Götz" von Berlichingen in the sixteenth century (Figure 1B).

\section{HOW ARE "ACTIVE" PROSTHESES DIFFERENT?}

Active prostheses allow the user to grasp objects, using specific movements of the body without the help of another hand. There are two types of active prostheses: body-powered and externally-powered. 
Figure 1

Evolution of hand prostheses. (A) This is an ancient wooden hand prosthesis from Egypt. (B) The fingers of this medieval mechanical iron hand could be locked, allowing the knight to hold the reigns of his horse while riding. (C) This myoelectric hand is as small and light as a natural hand. It can move thumb and index finger individually, and middle, ring and little finger together. (A) BY-NC-SA @ L Leeds Museums and Galleries;

(B) CC Attribution 3.0 Unported,

Generallandesarchiv Karlsruhe 498-1 Nr. 5110 Bild 1; (C) reproduced with permission from Prensilia S.r.l.

\section{MYOELECTRIC}

Using the electrical energy of muscles ("myo" = Greek for "muscle").

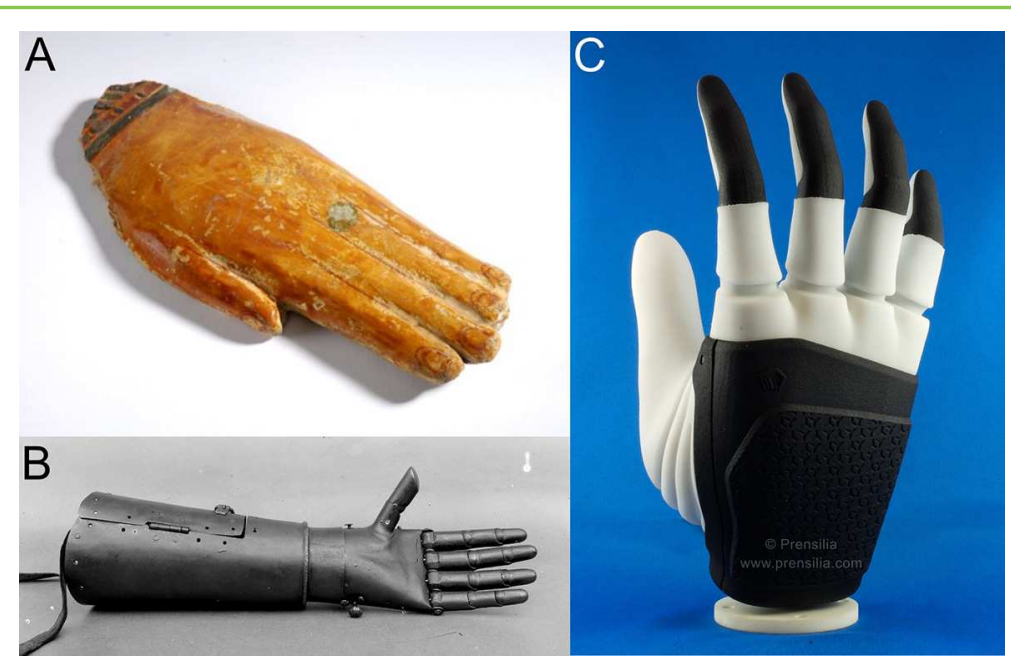

Figure 1

Body-powered prostheses, invented in the nineteenth century, are usually attached to the body with a harness. The hands or hooks at the end are opened and closed through body movements, like stretching out the arm (Figure 2). These prostheses are made from plastic, metal, and fabric for the straps of the harness.

Externally-powered active prostheses have been widely used since the 1960s. They are called "externally-powered," because they need an external power source, a battery. These types of prostheses are the complex robotic hands and arms that you sometimes see in movies or computer games (Figure 1C). These prostheses are made from plastics, metal, and many electrical components, like motors and microprocessors. These devices are also called "myoelectric" prostheses. "Myo" comes from the Greek and means muscle. When we move our muscles, small electrical fields are generated around them, which can be measured by electrodes. By placing an electrode on the skin over a muscle, we can measure if and how much the muscle is moving. The measured electrical signal is sent to the prosthesis through wires. These "myoelectric" signals tell the prosthesis whether to open or close and how fast to move (Figure 3).

Scientists are trying to find ever better ways of using these myoelectric signals to control prostheses, such as making control easier and enabling more movements than just open and close, for example, moving individual fingers [2].

A very recent development in upper limb prosthetics is called "osseointegration" (from the Latin "os," meaning bone). In this procedure, the prosthesis is not attached to a socket that is pulled over the stump, as is used for other kinds of active prostheses. Instead, screws are implanted into the bones of the arm, and the prosthetic hand is directly attached to the bone via these screws-similar to our 
Figure 2

Most body-powered prostheses can be opened by pulling on a cable, similar to brakes on a bicycle. Reaching out with the arm or rounding the shoulders pulls on the cable (blue) that opens the prosthesis. When the arm is pulled back and the tension on the cable is released, an elastic band or a spring closes the prosthesis automatically.

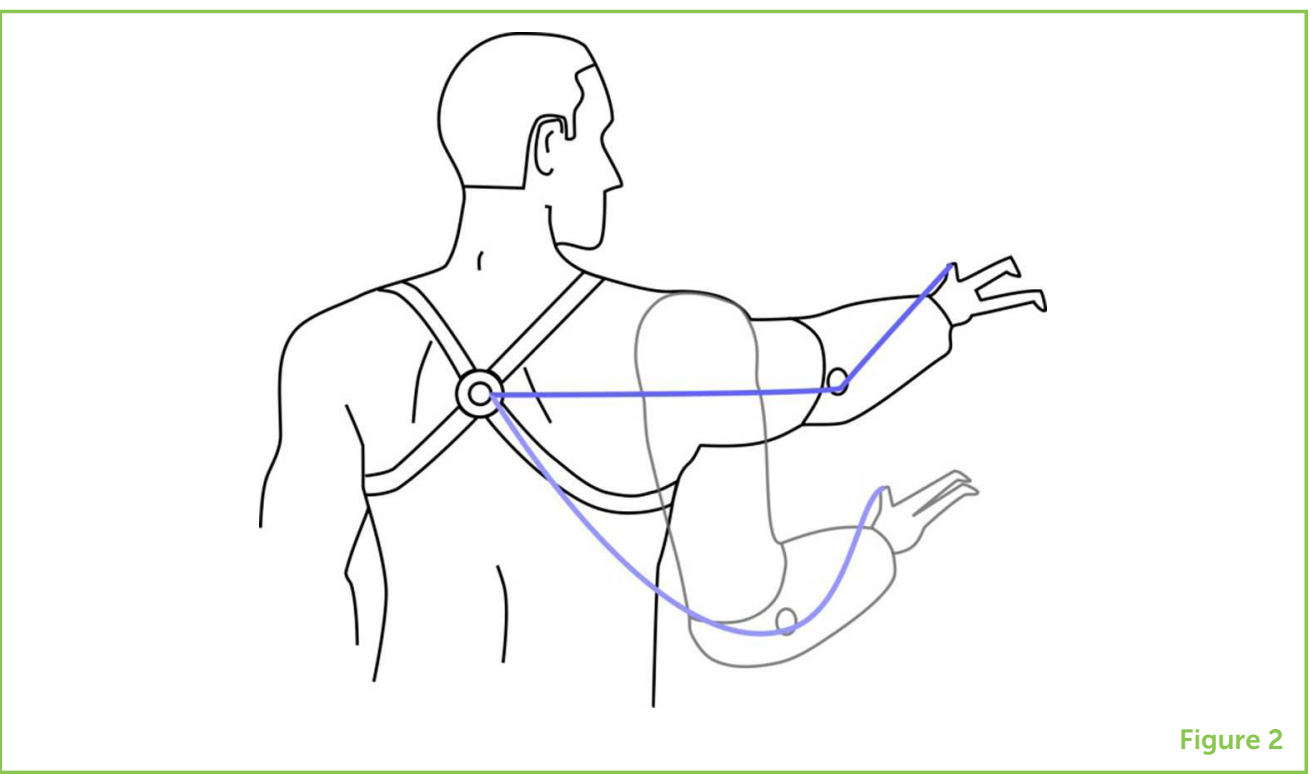

natural hands (see 0:14-1:12 in [4]). However, the surgery and the following therapy are very demanding for the patient.

\section{WHICH PROSTHESIS IS THE BEST?}

Which prosthesis to choose is partly personal preference, and partly determined by the amount of money the user has to spend on the prosthesis [3]. Body-powered prostheses are costlier than cosmetic prostheses (Table 1). Myoelectric hand prostheses cost even more, and without health insurance, few people can afford them. Myoelectric prostheses are also heavier than the other types, and their batteries need to be recharged daily. Further, myoelectric control requires healthy muscles and some training in order to operate them properly. Body-powered prostheses restrict the range of movement of arm and shoulders due to the harness but are more robust and allow heavier objects to be picked up and moved. Cosmetic prostheses do not restrict range of movement, they are light, and they usually look very realistic, but they do not allow the user to actively grasp anything. Some people prefer to use simple prostheses rather than complex robotic hands, which can break more easily and are difficult to repair.

Modern myoelectric prostheses can move the fingers of the hand into different positions, allowing for different ways of grasping (see 1:28-1:38 and 2:22-2:59 in [4]). This can make grasping easier, and fewer "compensatory movements" are necessary. Compensatory movements are unnatural movements that are necessary because the prosthesis cannot move like a natural arm or hand [5]. For example, to pick up something flat from the side of a table, the elbow of a person wearing a simple prosthesis needs to be lifted sideways to compensate for the missing wrist rotation. Modern myoelectric 


\section{Figure 3}

When only the hand is missing, the muscles in the forearm are used to control myoelectric prostheses. Imagining bending the wrist away generally opens the prosthesis. Imagining bending the wrist toward the body then closes the prosthesis again.

Table 1

Estimated costs for prosthetic arms in the United States. The prices may vary strongly between different countries.

\section{SENSOR}

A device that reacts to a physical stimulus (for example, pressure) and sends out information about it.

\section{FEEDBACK}

(SPECIFICALLY FOR PROSTHESES)

Information about the prosthesis returned to the person using the prosthesis.

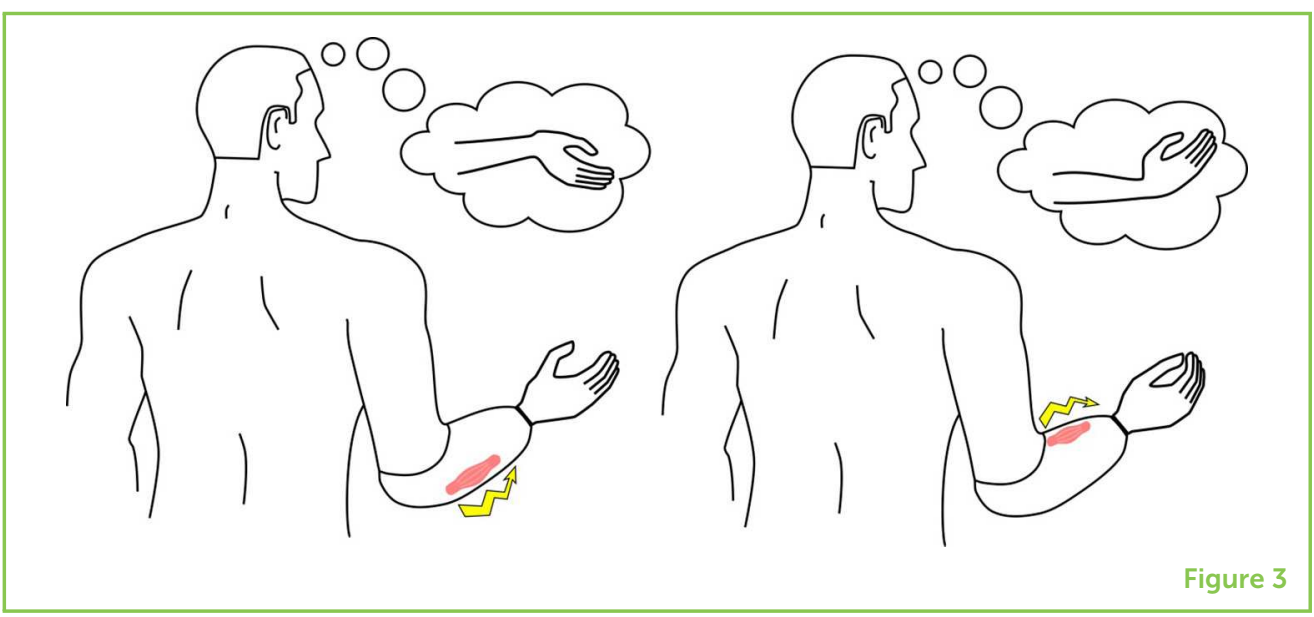

Device type

Estimated cost (in US Dollars)

\section{COSMETIC}

Below elbow

From under $\$ 1,000$

Above elbow

$\$ 3,000-5,000$

\section{BODY-POWERED}

Below elbow

$\$ 4,000-10,000$

Above elbow

$\$ 5,000-10,000$

\section{EXTERNALLY-POWERED/MYOELECTRIC}

Below elbow

$\$ 20,000-50,000$

Above elbow

prostheses have thumbs that can move to close on top of the index finger to hold something flat, making it unnecessary to lift the elbow. Recent research says that a moveable wrist is even more helpful for reducing compensatory movements [5].

Because of these different upsides and downsides, many people use two or more prostheses [1].

\section{CAN YOU FEEL WITH A ROBOTIC HAND?}

One big open question is how to feel with prostheses [2, 6]. People using body-powered prostheses can feel the tension of the cable moving the prosthesis, so they can estimate the grasping force somewhat. Myoelectric prostheses can be fitted with sensors to do things like record the grasping force at the fingertips, but scientists do not yet know how to give the information from the sensors back to the prosthesis user.

This information-called "feedback" - needs to be provided in a meaningful way. There are two different approaches to providing feedback: invasive and non-invasive [6]. Both have upsides and downsides. 
"Invasive" means that the prosthesis-user needs to have surgery to receive this kind of feedback. Most commonly, researchers implant electrodes around, in, or through the nerve in the stump, to stimulate the nervous system directly. The aim is to restore natural feedback through direct nerve stimulation. After all, the natural sensors in the human hand also send their information through the same nerves to the brain. But this technique has not yet been successful.

"Non-invasive" feedback, by contrast, does not require surgery. Common ways to provide non-invasive feedback are electrical stimulation of the skin, vibration on the skin, or devices that push, pull, or squeeze the skin. But, this does usually not reproduce natural sensation. For example, scientists place a vibrating motor on the skin; when the prosthesis is touched, the motor vibrates, similar to what happens when a cellphone receives a message. We call this "sensory substitution," because one kind of sensory information (the natural sense of touch) is replaced ("substituted") with another (the vibration). This substitution is not something the brain will naturally understand, so it needs to be learned. It would be ideal if we could, instead, reproduce natural sensations in a non-invasive way.

\section{CONCLUSION}

Prostheses are not strictly necessary in everyday life, but many people choose to wear some type of prosthesis. All types of prostheses can restore the appearance of having two hands, to some extent. Active prostheses can further restore some ability to touch, grasp, and hold objects. Myoelectric hands are becoming ever more dexterous and good-looking, but they are expensive. To restore sensation with these robotic hands, we need to find a way to send the information from the sensors to the user in a meaningful way. Many researchers are working on this problem and making huge progress, but there is still no hand prosthesis that restores natural sensation.

\section{REFERENCES}

1. Ostlie, K., Lesjø, I. M., Franklin, R. J., Garfelt, B., Skjeldal, O. H., and Magnus, P. 2012. Prosthesis use in adult acquired major upper-limb amputees: patterns of wear, prosthetic skills and the actual use of prostheses in activities of daily life. Disabil. Rehabil. Assist. Technol. (2012) 7:479-93. doi: 10.3109/17483107.2011.653296

2. Cordella, F., Ciancio, A. L., Sacchetti, R., Davalli, A., Cutti, A. G., Guglielmelli, E., et al. 2016. Literature review on needs of upper limb prosthesis users. Front. Neurosci. 10:1-14. doi: 10.3389/fnins.2016.00209

3. Carey, S. L., Lura, D. J., and Highsmith, M. J. 2015. Differences in myoelectric and body-powered upper-limb prostheses: systematic literature review. J. Rehabil. Res. Dev. 52:247-62. doi: 10.1682/JRRD.2014.08.0192

4. DeTOP. 2018. DeTOP Project Official Video. YouTube.com. Available online at: https://www.youtube.com/watch?v=6WQiJPexEDM (accessed April 6, 2019). 
5. Montagnani, F., Controzzi, M., and Cipriani, C. 2015. Is it finger or wrist dexterity that is missing in current hand prostheses? IEEE Trans. Neural Syst. Rehabil. Eng. 21:1-10. doi: 10.1109/TNSRE.2015.2398112

6. Schofield, J. S., Evans, K. R., Carey, J. P., and Hebert, J. S. 2014. Applications of sensory feedback in motorized upper extremity prosthesis: a review. Expert Rev. Med. Dev. 13:1-13. doi: 10.1586/17434440.2014.929496

SUBMITTED: 12 February 2019; ACCEPTED: 28 May 2019; PUBLISHED ONLINE: 12 June 2019.

EDITED BY: Kelly Westlake, School of Medicine, University of Maryland, Baltimore, United States

CITATION: Engels LF and Cipriani C (2019) Nature's Masterpiece: How Scientists Struggle to Replace the Human Hand. Front. Young Minds 7:83. doi: 10.3389/frym. 2019.00083

CONFLICT OF INTEREST STATEMENT: CC holds shares in Prensilia Srl, a company that manufactures robotic hands as the one in Figure $1 \mathrm{C}$.

The remaining author declare that the research was conducted in the absence of any commercial or financial relationships that could be construed as a potential conflict of interest.

COPYRIGHT ( 2019 Engels and Cipriani. This is an open-access article distributed under the terms of the Creative Commons Attribution License (CC BY). The use, distribution or reproduction in other forums is permitted, provided the original author(s) and the copyright owner(s) are credited and that the original publication in this journal is cited, in accordance with accepted academic practice. No use, distribution or reproduction is permitted which does not comply with these terms.

\section{YOUNG REVIEWERS}

\section{IIS G. PEANO, AGE: 15}

We are a group of 11 students from different classes of a high school located in Florence. Our names are: Tommaso, Irene, Luna, Samuele, Alessio, Martina, Giselle, Ashleyn, Nada, Noemi, and Aida. Although our school is more focused in studying and learning foreign languages, we are particularly fascinated by science. We really enjoyed working with our science mentors, Elena and Luca, and our teacher Riccardo. We hope that with our suggestions more students like us can appreciate this article.

\section{LICEO VENDRAMINI, AGE: 15}

We are a class of 27 students, 15 years old, in a Scientific High School located in Pordenone, Italy. We are very curious and creative minds, in particular when studying science. We always perform a lot of questions to better understand a new concept. For this reason, we like to get involved as young reviewers. 


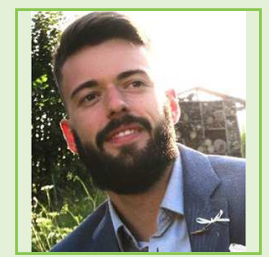

\section{AUTHORS}

\section{LEONARD F. ENGELS}

I am a Ph.D. student at the Artificial Hands Area of the BioRobotics Institute, where I work on restoring feedback to prosthesis users. I became fascinated in the subject when I saw a video of a woman dancing on robotic leg prostheses. Before I started working on hand prostheses, I studied Neuroscience to find out how the brain works. Now I try to make the brain believe that it can feel with a robotic hand. When I am not working in the lab, I like to go hiking in the mountains. *leonard.engels@santannapisa.it

\section{CHRISTIAN CIPRIANI}

I am a Professor of Bioengineering and head of the Artificial Hands Area at the BioRobotics Institute. Since 2017, I also serve as the Director of the Institute. I have been working on hand prostheses and robotic hands since 2005. Currently, I coordinate four large national and international research projects, in which I try to design and build the hand and arm prostheses of the future. 